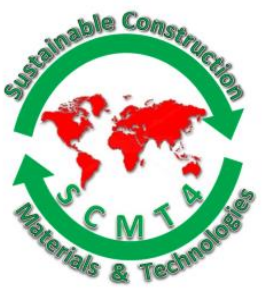

SCMT4

Las Vegas, USA, August 7-11, 2016

\title{
Out of Plane Experimental Behavior of T-Shaped Full Scale Masonry Orthogonal Walls Strengthened with Innovative Composite Systems
}

\author{
Maddaloni G. ${ }^{1 a}$, Balsamo A. ${ }^{1 b}$, Di Ludovico M. ${ }^{1 c}$, and Prota A. 1d \\ ${ }^{1}$ Department of Structures for Engineering and Architecture, University of Naples "Federico II", via \\ Claudio, 21 - 80125 - Naples, Italy. \\ ${ }^{1 a}$ Email: <gennaro.maddaloni@unina.it>, ${ }^{1 b}$ Email: <diludovi@unina.it, ${ }^{1 c}$ Email:<albalsam@unina.it>, \\ ${ }^{1 d}$ Email: <aprota@unina.it>.
}

\begin{abstract}
A large number of masonry buildings have been designed for gravity loads or with reference to obsolete seismic provisions; in case of seismic events the high vulnerability of these structures is dramatically pointed out, especially in structures without effective structural connections between bearing walls. Indeed, in case of seismic actions, the structural connections are crucial to achieve a favorable distribution of horizontal loads and to avoid out-of-plane mechanisms. In order to investigate on the effectiveness of an innovative strengthening solution to improve the connection between orthogonal walls, an experimental program has been carried out on a full scale T-shape masonry specimen under the simultaneous application of axial load and horizontal displacements. Monotonic and cyclic tests have been performed on unreinforced tuff masonry specimen, designed with a poor connection between the two orthogonal walls. After this round of tests the specimen has been repaired and strengthened with an innovative technique in order to improve the connections between walls. The strengthening solution consisted of grouted anchors made by hollow CFRP pultruded carbon tubes wrapped with longitudinal and spiral stainless steel fabrics to increase the bond between mortar and tubes. The strengthening solution and the installation procedure are described and illustrated in the paper. Furthermore, it reports the main experimental results at global and local level as well a comparison between the out-of-plane behavior of the unreinforced and the strengthened after repair specimen.
\end{abstract}

\section{INTRODUCTION}

The experiences of recent earthquakes have clearly shown that existing masonry buildings, especially historical and monumental buildings, resulted the most vulnerable to seismic actions. The types of collapse are mostly characterized by out of plane mechanisms because of the poor effectiveness of connections between orthogonal walls. The assessment of the seismic capacity of existing masonry structures requires the knowledge and the evaluation of the effectiveness of structural connections between orthogonal walls and between walls and floors. In spite of the importance of connections, few experimental programs have been carried out to investigate on the behavior of poorly connected orthogonal bearing masonry walls under seismic actions. By contrast, several experimental programs involved the out-of-plane behavior of single 
walls [ABK 1981, Baggio and Masiani 1991, Bariola et al. 1990, Lam et al. 1995, Simsir at al. 2004, Meisl et al. 2006]. However, experimental studies on the effectiveness of structural connections are still lacking. Recently, an experimental program was carried out on full-scale T-shaped and corner masonry walls, strengthened with steel anchors [Paganoni and D'Ayala 2014].

Traditional strengthening solutions to increase the effectiveness of poor connections are: insertion of steel ties to improve the collaboration among walls; the use of "reinforced stitching" technique with steel rods in orthogonal walls to improve the capacity of connections [Di Ludovico et al. 2016]. The latter technique presents several critical issues as the steel corrosion of bars and the bond between steel rods and surrounding masonry. In order to overcome these critical issues, an innovative strengthening technique has been investigated and discussed in the present paper. In particular, it involves the use of hollow pultruded carbon tubes (CFRP) rather than steel rods as connection system. The experimental behavior of a T-shaped full scale masonry wall with a poor connection between orthogonal walls, has been investigated in the as-built, repaired and repaired and strengthened configuration. The effectiveness of the proposed innovative strengthening solution is also strongly analyzed.

\section{EXPERIMENTAL PROGRAM}

A full scale T-shaped masonry wall has been designed in order to reproduce common orthogonal bearing walls of existing masonry structures. Furthermore, a poor connection between the orthogonal walls has been designed to simulate common execution practices. The dimensions of members and connections details were chosen to simulate a T-shaped connection of a tuff masonry building with three floors, as shown in Figure 1a. The specimen height is $1900 \mathrm{~mm}$, the width of the two orthogonal walls are $2000 \mathrm{~mm}$ and 1200 $\mathrm{mm}$ respectively (Figure 1b,c). The thickness of the two orthogonal walls (i.e. front wall and spine wall) is $400 \mathrm{~mm}$.

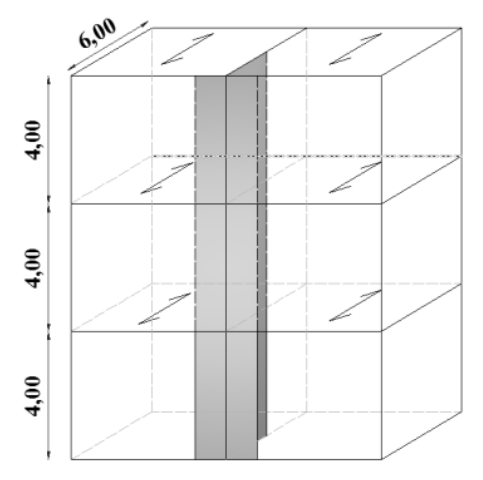

a)

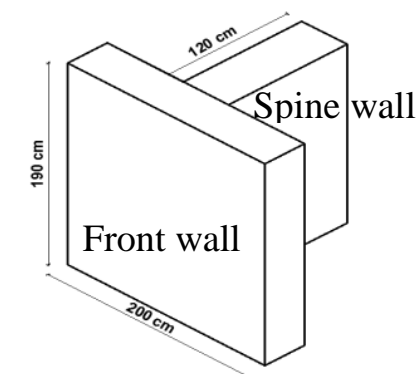

b)

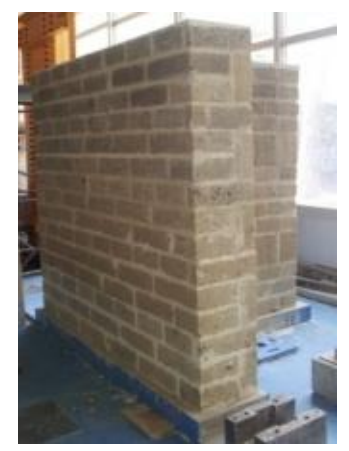

c)

Figure 1. Designed specimen: a) Building scheme; b) Specimen dimensions; c) As-Built specimen.

The masonry specimen is made by yellow regular Neapolitan blocks (370x250x105 mm) with a traditional regular texture; the mortar thickness is about $10-15 \mathrm{~mm}$. In order to reproduce a weak connection between the two orthogonal walls, the connection between front and spine wall consists of $105 \mathrm{~mm}$ in plan view (i.e. about $1 / 3$ of the wall thickness) and it is not constant along the wall height (i.e. 10 on 15 courses along the specimen height).

The Experimental program involved 3 tests:

- $S 1$, constant vertical loads and monotonic horizontal displacements on the "as built" specimen;

- $S 2$, constant vertical loads and cyclic horizontal displacements on the repaired specimen;

- S3, constant vertical loads and cyclic horizontal displacements on the repaired and FRP strengthened specimen. 


\section{TEST SETUP}

The experimental tests were carried out by the simultaneous application of constant vertical load and horizontal displacements. In particular, vertical loads were applied on both front and spine walls; the vertical load on front wall was $120 \mathrm{kN} / \mathrm{m}$. It has been computed as the gravity load given by three floors and two masonry levels (Figure 1a). The vertical load on the spine wall was $40 \mathrm{kN} / \mathrm{m}$ since it only simulates the gravity load of two masonry levels (Figure 1a). A constant vertical load was applied on the specimen as a reaction to tensile forces provided by hollow hydraulic jacks on two high-strength steel bars connected to semispherical hinges at the foundation block and to a steel reaction device at the top of the wall (Figure 2). The specimen was placed on a steel hollow base, filled with mortar, in order to reproduce the foundation. The horizontal loads were applied by means of a servo-hydraulic actuator equipped with $100 \mathrm{kN}$ capacity load cell, compatible with the expected range of test forces. The horizontal servo-hydraulic actuator was located at a distance of $1620 \mathrm{~mm}$ from the specimen foundation (Figure 2a).
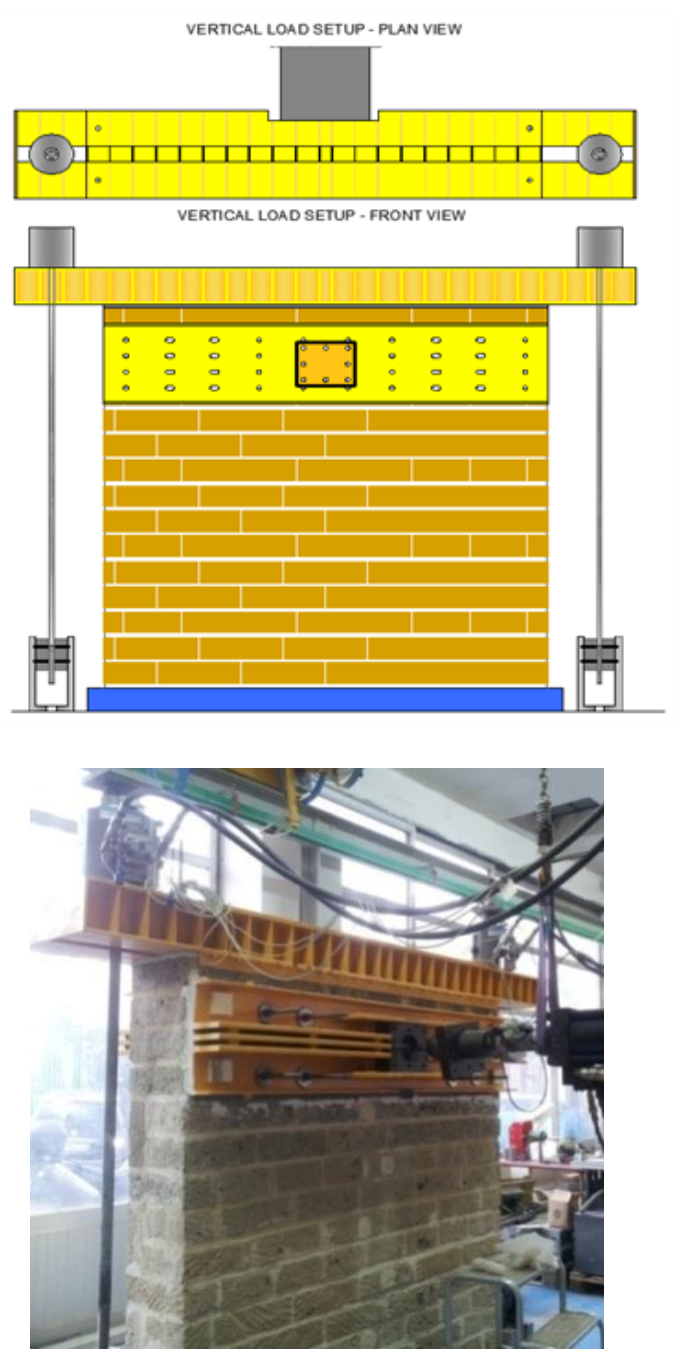

(a)
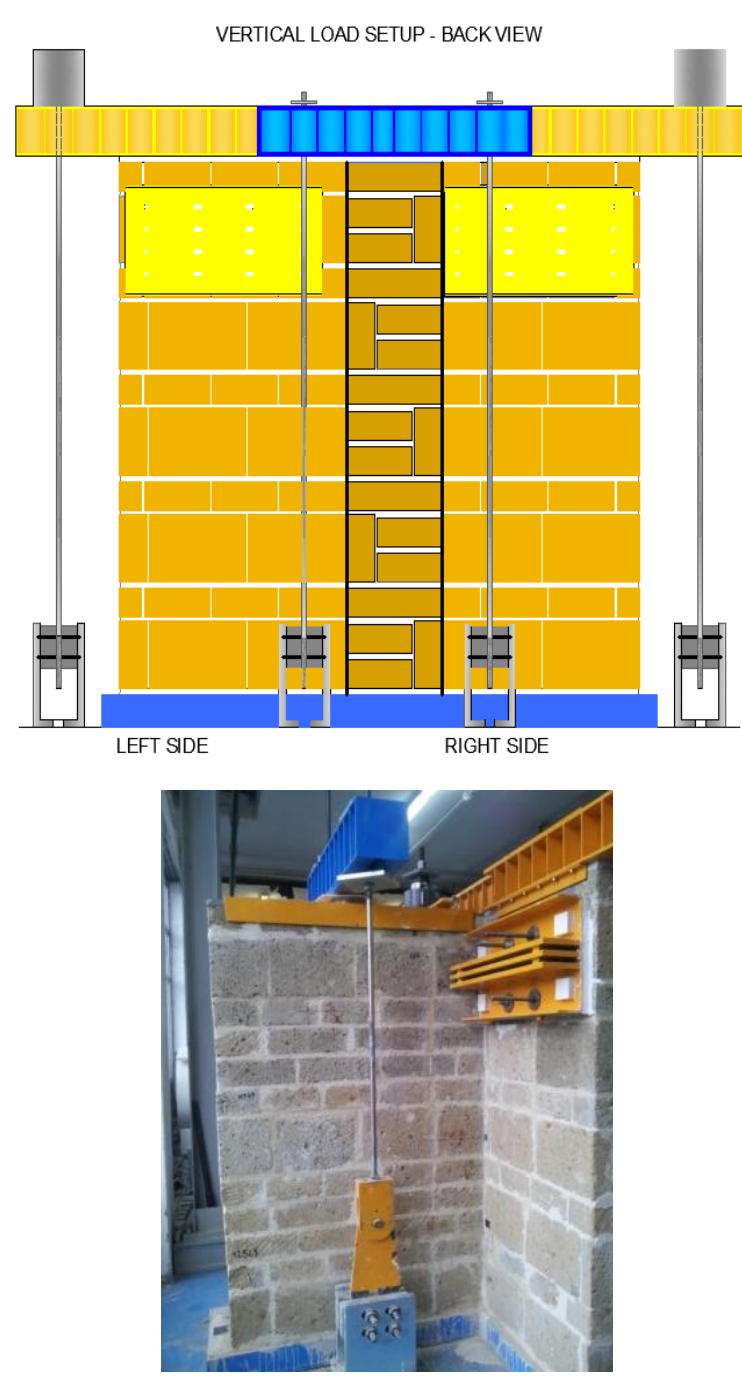

(b)

Figure 2. Test setup: a) front wall; b) spine wall 


\section{EXPERIMENTAL BEHAVIOUR OF AS BUILT AND REPEIRED SPECIMEN}

The as-built specimen was firstly tested by applying a monotonic pattern of horizontal displacements in out of plane direction (i.e. orthogonal to front wall) at a constant rate, v $=0,01 \mathrm{~mm} / \mathrm{s}$, up to $8 \mathrm{~mm}$ (test $S 1$ ). Indeed, at this horizontal displacement, corresponding to a drift of $0.49 \%$, significant cracks were observed at the connection between the two orthogonal walls; at this drift the strength peak of the horizontal force drift curve was attained. The drift has been calculated as the ratio between the horizontal imposed displacement and the distance between the specimen foundation and servo-hydraulic actuator location, 1620 $\mathrm{mm}$. The experimental horizontal force - drift relationship is shown in Figure 2.

At the end of $S 1$ test, the specimen was repaired with super-fluid mortar injection of cracks and a cyclic test (test S2) was carried out on the repaired specimen; the cyclic actions consisted of horizontal displacements in out of plane direction as summarized in Table 1; the table reports the maximum displacement achieved at each cycle, $d_{\max }$, the drift and the horizontal displacement rate, $v$. Each cycle was repeated three times from 0 to $d_{\max }$ and from $d_{\max }$ to 0 .

Table 1. Cyclic tests loading path (test S2 and S3)

\begin{tabular}{|c|c|c|c|}
\hline \multirow{2}{*}{ Cycle } & $\mathbf{d}_{\max }$ & drift & $\mathbf{v}$ \\
\cline { 2 - 4 } & {$[\mathbf{m m}]$} & {$[\%]$} & {$[\mathbf{m m} / \mathbf{s e c}]$} \\
\hline I & 0.5 & $0.03 \%$ & 0.03 \\
\hline II & 1.0 & $0.06 \%$ & 0.03 \\
\hline III & 3.0 & $0.19 \%$ & 0.10 \\
\hline IV & 5.0 & $0.31 \%$ & 0.10 \\
\hline V & 7.0 & $0.44 \%$ & 0.10 \\
\hline VI & 9.0 & $0.56 \%$ & 0.10 \\
\hline VII & 11.0 & $0.69 \%$ & 0.10 \\
\hline VIII & 13.0 & $0.81 \%$ & 0.10 \\
\hline IX & 15.00 & $0.94 \%$ & 0.10 \\
\hline X & 17.00 & $1.06 \%$ & 0.10 \\
\hline XI & 19.00 & $1.19 \%$ & 0.10 \\
\hline XII & 23.00 & $1.44 \%$ & 0,20 \\
\hline
\end{tabular}

The test ended at cycle VIII corresponding to a horizontal maximum displacement of $13 \mathrm{~mm}$ (i.e. drift of $0.81 \%)$. At this stage a significant strength reduction was recorded and significant cracks, larger than those observed in S1 test, developed at the interface between the two orthogonal walls. The experimental horizontal force - drift relationship is shown in Figure 2 along with the envelope curve (blue dashed line). Furthermore, two horizontal dashed lines are reported in Figure 2; they report the theoretical horizontal forces to activate the overturning in case of: ineffective connection between orthogonal walls leading to a rigid rotation of the front wall around an horizontal hinge at the base of front wall (out of plane failure Mechanism I); and fully effective connection between orthogonal walls leading to the overturning of a part of the spine wall with a diagonal, $45^{\circ}$ inclination angle, crack (out of plane failure Mechanism II).

The figure shows that the experimental trend of horizontal force - drift relationship recorded on $S 2$ was very similar to that of specimen $S 1$. This confirmed that the repair was effective to restore the initial stiffness of T-shaped masonry wall.

The specimen behavior was characterized by a first linear elastic branch up to horizontal force $\mathrm{F}=35 \mathrm{kN}$, corresponding to a drift $0,16 \%$ in $S 1$ test and $0,19 \%$ in $S 2$ test; by increasing the horizontal out of plane 
displacement, the curve slope decreased and the peak force $\left(\mathrm{F}_{\max }=48 \mathrm{kN}\right)$ was attained at a drift $0,52 \%$ and $0,44 \%$, in $S 1$ and $S 2$ test, respectively. Besides, in $S 2$ test a post-peak behavior was observed up to a drift $0,81 \%$. Note that, in both tests, the change of slope of the horizontal force - drift curve started at horizontal force values very close to that predicted as the theoretical force to activate out of plane failure Mechanism. This confirms that the connection, even if not fully effective, was sufficient to delay the overturning of the front wall according to Mechanism I.

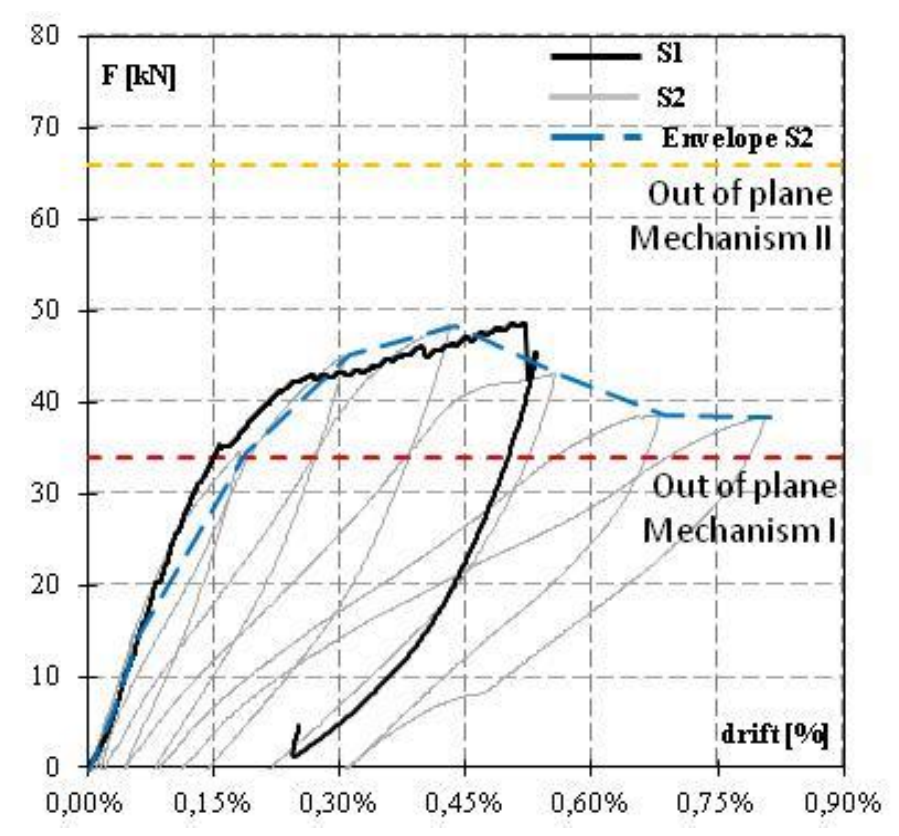

Figure 2. Force - drift relationship: test S1 and S2

At the end of test S2 it was possible to observe a crack pattern characterized by the overturning of front wall around an horizontal hinge located at about $1 / 3$ of the specimen height; this overturning also involved a part of the spine wall with the formation of a vertical crack at a distance of about $400 \mathrm{~mm}$ from the front and spine wall interface. Thus the failure mechanism was similar to that expected for Mechanism II but with a lower part of spine wall involved in the overturning mechanism if compared to the case of full effective connection between orthogonal walls (diagonal cracks in spine wall inclined at $45^{\circ}$ ).

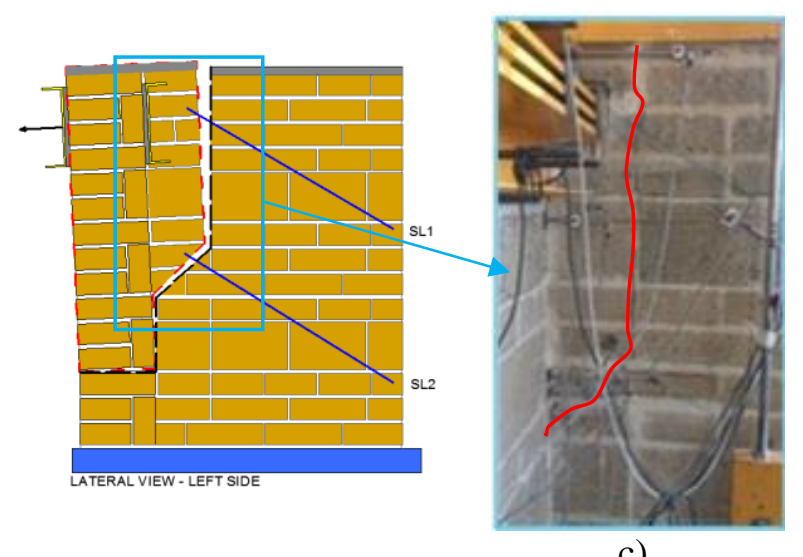

c)

Figure 3. Damage pattern at the end of test S2 


\section{EXPERIMENTAL BEHAVIOR OF FRP STRENGHTENED SPECIMEN}

At the end of test S2, the specimen was firstly repaired and then strengthened by using an innovative technique to replace the traditional reinforced stitching based on the use of steel rebars; the repair consisted of injection of cracks with superfluid mortar, while the strengthening solution involved the use of hollow pultruded carbon fibre tubes, external diameter equal to $10 \mathrm{~mm}$, as an alternative solution to steel rebars. The CFRP tubes were inserted in holes at the connection between the two orthogonal walls and grouted by means of mortar. According to provisions provided by ACI 440.3R-04, six tests were carried out in order to investigate the tensile strength of hollow CFRP pultruded carbon tube. The outcomes of tensile tests, elaborated according to UNI EN 2561-2001, are summarized in Table 2.

Table 2. Tensile tests on hollow pultruted carbon tubes

\begin{tabular}{|c|c|c|c|}
\hline \multirow{2}{*}{ Specimen } & $\boldsymbol{\sigma}_{\mathbf{u}}$ & $\mathbf{E}_{\mathbf{f}}$ & $\boldsymbol{\varepsilon}_{\mathbf{u}}$ \\
\cline { 2 - 4 } & {$[\mathbf{M P a}]$} & {$[\mathbf{M P a}]$} & {$[-]$} \\
\hline 1 & 2,958 & 151,781 & 1.9 \\
\hline 2 & 2,687 & 152,180 & 1.8 \\
\hline 3 & 2,891 & 148,897 & 1.9 \\
\hline 4 & 2,749 & 149,313 & 1.8 \\
\hline 5 & 2,867 & 146,609 & 2.0 \\
\hline 6 & 2,878 & 162,468 & 1.8 \\
\hline Mean [MPa] & 2,838 & 151,874 & 1.9 \\
\hline St.Dev. [MPa] & 100 & 5,576 & 0.1 \\
\hline CV [\%] & 3.54 & 3.67 & 4.79 \\
\hline
\end{tabular}

In order to increase the transverse strength of tubes and the bond between injected mortar and tubes, they were wrapped by using longitudinal and spiral stainless steel fabrics (average failure load $3600 \mathrm{~N}$ ); the steel fabric was installed around the tube by using an epoxy based mortar as shown in Figure 4.

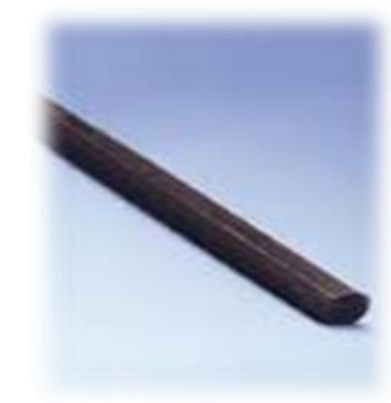

Hollow pultruded carbon fibre tube

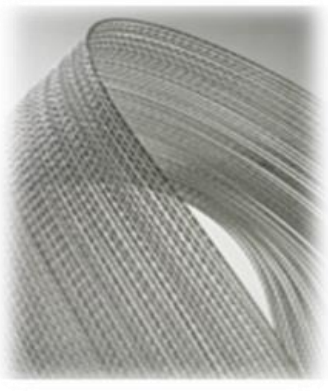

Stainless steel fabrics

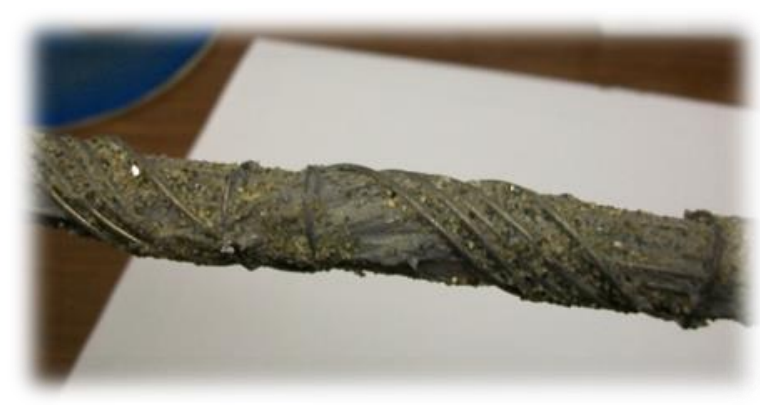

Reinforced tube

Figure 4. Reinforced hollow pultruded CFRP tube

The CFRP tubes reinforced with stainless steel fabric were inserted in $30 \mathrm{~mm}$ diameter holes with a length of $1200 \mathrm{~mm}$; the layout of holes is depicted in Figure 6. The holes were located along two vertical lines in the connection zone between the front and the spine walls; the horizontal spacing of vertical holes was $130 \mathrm{~mm}$ while the vertical spacing of holes was $250 \mathrm{~mm}$, see Figure 5. 


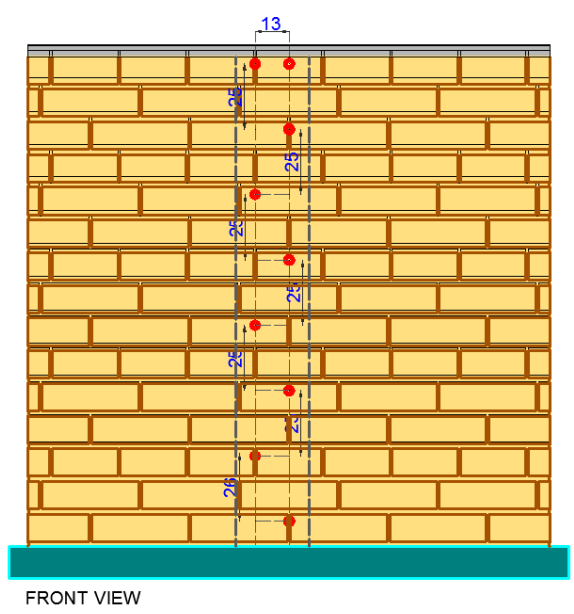

\section{Figure 5. CFRP connection: holes location}

The installation of the strengthening technique involved the following steps, see Figure 6: i) drilling of holes with $30 \mathrm{~mm}$ diameter, $1200 \mathrm{~m}$ length (Figure 6a); ii) filling of the holes by water at low pressure in order to clean the holes - 24 hours before the injection - (Figure 6b); iii) installation of reinforced tubes in the holes and relevant injection nozzles (Figure 6c); iv) installation of pipes to remove air and sealing the holes (Figure 6d); v) injection of superfluid, cement free, fillerized hydraulic binder, based on lime and Eco-Pozzolan, with manual pump (Figure 6e); vi) removing of injection nozzles and sealing of holes with mortar (Figure 6f).

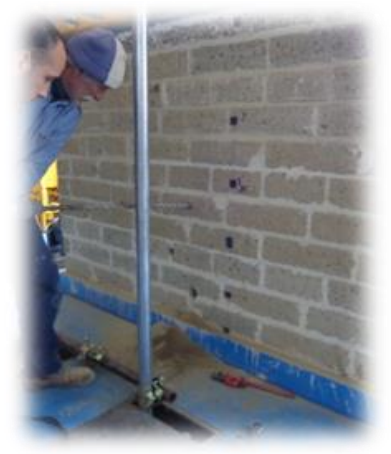

a) Drilling of holes

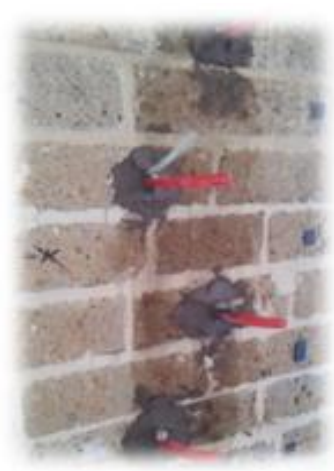

d) Sealing of holes

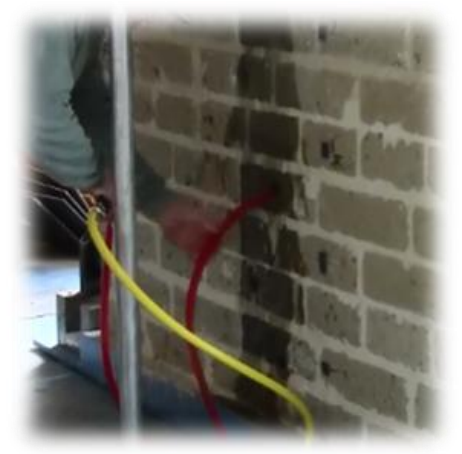

b) Filling of holes

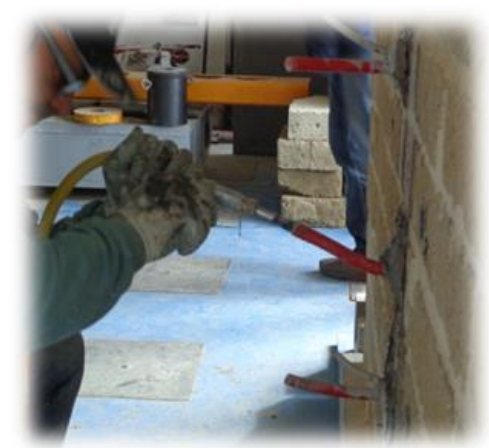

e) Injection of mortar

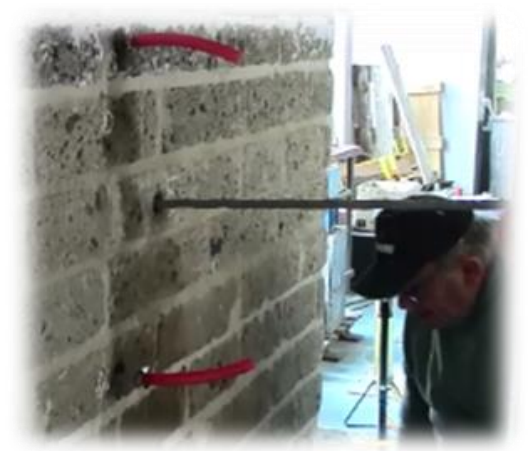

c) Insertion of reinforced CFRP tubes

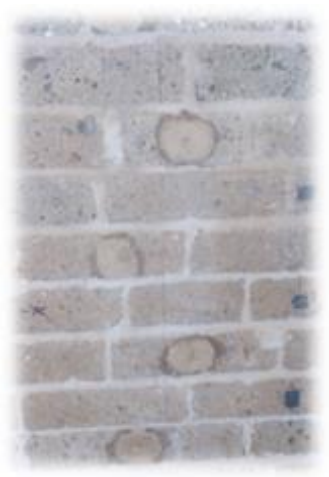

f) Final sealing

Figure 6. Strengthening installation phases 
The strengthened specimen was tested by the simultaneous application of vertical constant loads and horizontal displacements, as for test $S 2$. The loading path of cyclic horizontal displacements in out of plane direction is reported in Table 1; the test on the strengthened specimen, test $S 3$, ended at cycle XII corresponding to a horizontal maximum displacement of $23 \mathrm{~mm}$ (i.e. drift of 1.44\%). The horizontal force - drift relationship is reported in Figure 8; the envelope curve is depicted by using a dashed line. The horizontal force - drift envelope curve has an increasing trend up to the maximum drift. The curve is characterized by two linear branches with a different slope: the first branch reached a force of $73 \mathrm{kN}$, and a corresponding drift of $0,31 \%$; the second branch had a lower slope with respect to the first one and ended at a force of $132 \mathrm{kN}$, corresponding to a drift of $1.44 \%$. The strength increased by a factor of 2.75 with respect to previous tests. Furthermore, the maximum horizontal force was greater than the theoretical one related to the formation of failure Mechanism II. No significant cracks were observed on the specimen up to the end of the test; a rigid rotation of the T-shaped masonry specimen was observed, as confirmed by the cyclic opening and closing of a crack at the base of the specimen on the spine wall (see Figure 8).

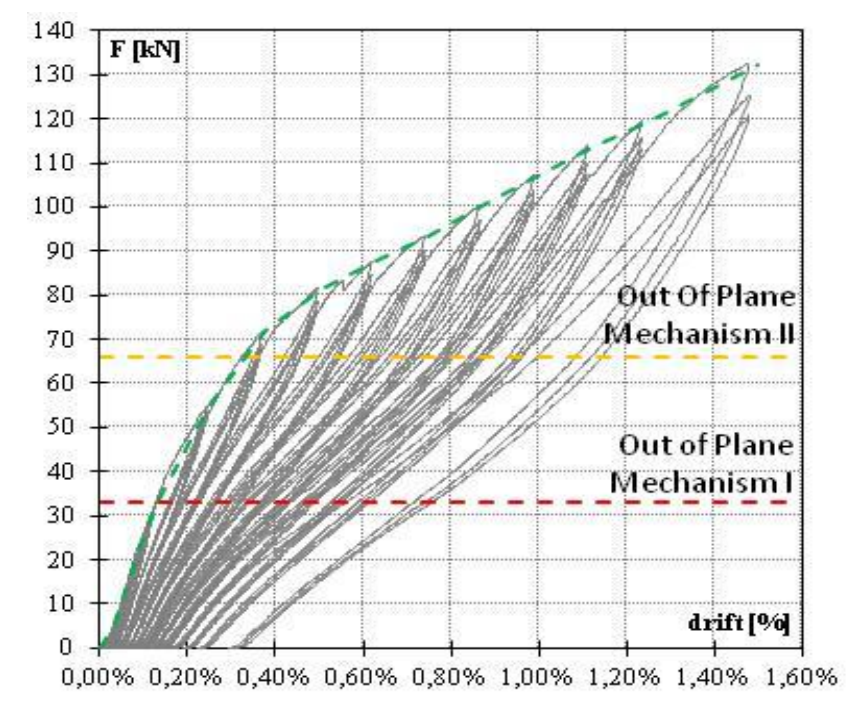

Figure 7. Force - drift relationship: test S3
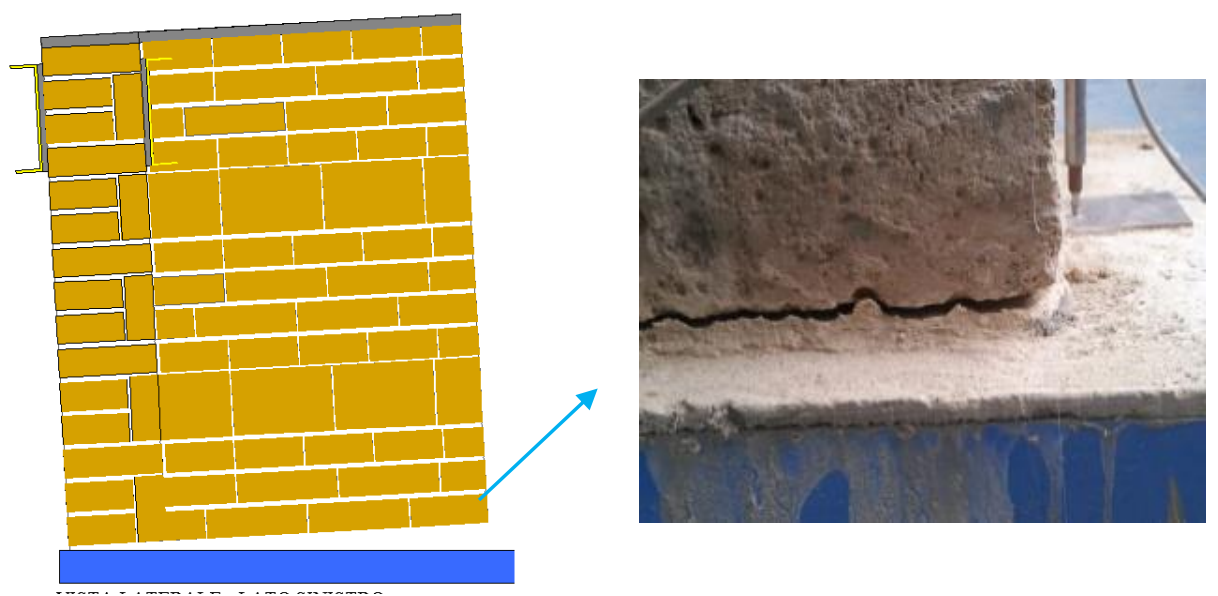

a) b)

Figure 8. Rigid rotation of the strengthened specimen with innovative composite system 


\section{CONCLUSION}

An experimental program has been carried out on full scale T-shaped masonry wall in order to investigate on the out of plane behavior of poorly connected orthogonal masonry walls and on the effectiveness of a new technique to delay or avoid out of plane mechanisms. A full scale T-shaped tuff masonry specimen has been designed and realized in order to simulate common connections between orthogonal walls in existing masonry buildings. The tests on the unreinforced specimens showed that: a poor connection was still able to avoid simple overturning of the front wall without any interaction with the spine wall; the maximum subassembly strength in terms of horizontal out of plane force was within a theoretical range of forces related to simple overturning (Mechanism I) and overturning involving a part of the orthogonal wall (Mechanism II); the overturning of the front wall started from a hinge located at about 1/3 of the specimen height and involved a part of the spine wall with the formation of a vertical crack at a distance of about 400 $\mathrm{mm}$ from the front and spine wall interface.

A new strengthening solution based on the use of CFRP pultruded tubes instead of steel rebars to improve the connection between the two orthogonal walls was investigated in the third test. The strengthening involved grouted anchors made by hollow CFRP tubes wrapped with longitudinal and spiral stainless steel fabrics to increase the bond between mortar and tubes. The strengthening solution allowed to significantly increase (by a factor of about 2.75) the horizontal force applied on the connection without the formation of any cracks at the interface between the orthogonal walls. The strengthening solution was effective to fully connect orthogonal walls as confirmed by the global behavior of the specimen mainly characterized by a rigid rotation. Even if further experimental evidences are needed to validate the strengthening solution, the experimental outcomes of the present study show that the proposed innovative strengthening technique may be a sound and effective solution to strongly improve the poor connection between orthogonal walls of existing masonry buildings.

\section{REFERENCES}

ABK (Agbabian Barnes Kariotis) (1981). Methodology for mitigation of seismic hazards in existing unreinforced masonry buildings: wall testing, out-of-plane. Topical Report 04, El Segundo (CA,USA): Agbabian Assoc.

Baggio, C. \& Masiani, R. (1991). Dynamic behaviour of historical masonry. Proceedings of the 9th International Brick/Block Masonry Conference, Berlin, Germany, 1991, 473-480.

Bariola, J., Ginocchio, J.F. \& Quiun, D. (1990). Out-of-plane seismic response of brick walls. 5th North American Masonry Conference. University of Illinois at Urbana-Champaign, June 3-6 1990, 1: 429-439.

Lam, N. T.K., Wilson, J. L. \& Hutchinson, G. L., 1995. The Seismic Resistance of Unreinforced Masonry Cantilever Walls in Low Seismicity Areas. Bulletin New Zealand National Society for Earthquake Engineering, 28(3): 179-195.

Simsir, C.C., Aschheim, M.A. \& Abrams, D.P., 2004. Out-of-Plane Dynamic Response of Unreinforced Masonry Bearing Walls Attached to Flexible Diaphragms. 13th World Conference on Earthquake Engineering, Vancouver, B.C., Canada, August 1-6, 2004, Paper No. 2045

Meisl, C.S., Elwood, K.J., Mattman, D.W. \& Ventura, C.E. (2006). Out-of-Plane Seismic Performance of Unreinforced Clay Brick Masonry Walls. 8th U.S. National Conference on Earthquake Engineering, San Francisco, California, USA, April 18-22, 2006, Paper No. 959.

Paganoni, S., D'Ayala, D. (2014). Testing and design procedure for corner connections of masonry heritage buildings strengthened by metallic grouted anchors. Engineering Structures 70 (2014) 278-293. 
Di Ludovico M, Prota A, Moroni C, Manfredi G, Dolce M., Reconstruction process of damaged residential buildings outside the historical centres after L'Aquila earthquake - Part I: light reconstruction. Bull Earthq Eng 2016. http://dx.doi.org/10.1007/s10518-016-9877-8. accepted for publication.

ACI 440.3R-04 "Guide Test Methods for Fiber-Reinforced Polymers (FRPs) for Reinforcing or Strengthening Concrete Structures".

UNI EN 2561 “Tensile Test Parallel To The Fibre Direction”. Ente Nazionale Italiano di Unificazione, European Committee for Standardization 2001. 